\title{
Oral Surgery: Mandibular Fracture Risk
}

Sir, A 28-year-old male patient presented to our maxillofacial department with an iatrogenic mandibular fracture following removal of an impacted lower right third molar tooth.

The extraction was carried out under local anaesthetic in a general dental practice setting. Upon delivery of the tooth, both dentist and patient heard "a crack". Subsequently, the patient's occlusion was deranged and mobility was evident in the right side of the mandible. The patient was referred to the maxillofacial department where imaging confirmed a fracture in the right angle of the mandible.

The following day, open reduction and internal fixation was carried out under general anaesthetic and the patient was discharged two days postadmission.

In light of the recent changes to the law regarding consent, we feel this case highlights the important implications for clinicians. The landmark decision in Montgomery $v$ Lanarkshire Health Board ${ }^{1}$, given by the UK Supreme Court on 11 March 2015, means that the "Bolam test" no longer applies to the issue of consent. This previously used test asked whether a clinician's conduct would be supported by a responsible body of medical opinion. However, the law now requires doctors to take "reasonable care to ensure that the patient is aware of any material risks involved in any recommended treatment." The definition of a "material risk" is one to which a reasonable person would be likely to attach significance to.

In this case, the risk of mandibular fracture was not discussed with the patient during the consent process. It can be argued that, due to the low incidence of mandibular fracture associated with the removal of teeth $(<0.005 \%)^{2,3,4}$, this need not be discussed during routine procedures. We believe this is now a perilous attitude in an increasingly litigious world. In the case of Rogers $v$ Whitaker ${ }^{5}$, an Australian court found the ophthalmologist to be negligent for failure to disclose the chance of blindness due to its remote risk $(0.007 \%)$. Whilst we respect that the loss of vision is a far greater morbidity than a mandibular fracture, we feel the latter would be deemed of significance by the majority of patients.

Care to predict and prevent fractures during exodontia is common practice amongst clinicians. The discussion regarding this presented case should focus on consent; our advice is that the rare risk of mandibular fracture is discussed with all patients before removal of lower third molar teeth. 


\section{Authors}

1. Shadi Basyuni

2. Ashley Ferro

3. Malcolm Cameron

University of Cambridge/Addenbrooke's Hospital, Cambridge

\section{$\underline{\text { Reference }}$}

1) Montgomery (Appellant) $v$ Lanarkshire Health Board (Respondent) (Scotland) [2015] UKSC 11.

2) Alling $C C$, Alling $R D$. Indications for management of impacted teeth. In Alling C C, Helfrick J F, Alling R D (eds) Impacted teeth. pp 46-64. Philadelphia: W B Saunders, 1993.

3) Perry P A, Goldberg M H. Late mandibular fracture after third molar surgery: a survey of Connecticut oral and maxillofacial surgeons. $J$ Oral Maxillofac Surg 2000; 58: 858-861.

4) Libersa P, Roze D, Cachart T, Libersa J C. Immediate and late mandibular fractures after third molar removal. J Oral Maxillofac Surg 2002; 60: 163-165.

5) Rogers $v$ Whitaker (1992) 175 CLR 479. 